Revista Bioética

\title{
PESQUISA
}

\section{Termo de consentimento livre e esclarecido na assistência à saúde}

Carolina Fernandes de Castro ${ }^{1}$, Alberto Manuel Quintana ${ }^{1}$, Luísa da Rosa Olesiak ${ }^{1}$, Mikaela Aline Bade München ${ }^{1}$

1. Departamento de Psicologia, Programa de Pós-Graduação em Psicologia, Universidade Federal de Santa Maria, Santa Maria/RS, Brasil.

\section{Resumo}

A bioética tem entre seus princípios a autonomia, base do consentimento informado, o qual é comprovado pelo termo de consentimento livre e esclarecido. Nesse documento a equipe de saúde esclarece o diagnóstico, prognóstico, os riscos e objetivos do tratamento sugerido ao paciente. Por meio de revisão de literatura, foram selecionados artigos que focalizam esse termo, e pela leitura do corpus percebem-se dificuldades da equipe de saúde em seu uso, sobretudo no que concerne ao seu objetivo, à linguagem utilizada e à maneira de apresentá-lo. Ademais, notou-se que o documento vem sendo aplicado visando a prevenção jurídica dos profissionais da saúde, principalmente médicos, em caso de erro técnico, uso que foge à proposta inicial.

Palavras-chave: Bioética. Consentimento livre e esclarecido. Autonomia pessoal.

\section{Resumen}

\section{Formulario de consentimiento informado en la asistencia sanitaria}

La bioética tiene entre sus principios la autonomía, base del consentimiento informado, que se confirma con el formulario de consentimiento libre e informado, documento en el que el equipo de salud aclara el diagnóstico, pronóstico, riesgos y objetivos del tratamiento sugerido al paciente. A través de una revisión literaria, se seleccionaron artículos que tratan del formulario de consentimiento. Al leer el corpus, se notó que los equipos de salud tienen dificultades con el documento, especialmente en lo que respecta a su objetivo, el lenguaje utilizado y el modo de presentación. Además, se constató que el formulario se ha aplicado con el objetivo de proteger legalmente a los profesionales de salud -sobre todo médicos-en caso de error técnico, uso que difiere de la propuesta inicial. Palabras clave: Bioética. Consentimiento informado. Autonomía personal.

\begin{abstract}
Informed consent form in healthcare

Bioethics has among its principles autonomy, the basis of informed consent, which is confirmed by the informed consent form. In this document, the health team clarifies the diagnosis, prognosis, risks and objectives of the treatment suggested to the patient. A literature review was conducted to select articles focusing on this document, and the resulting corpus shows that health teams struggle to use the informed consent form, especially regarding its purpose, the language used and how to present it. It was also noted that this form has often been applied for purposes other than its original one, such as the legal protection of healthcare providers, especially physicians, in case of technical errors.

Keywords: Bioethics. Informed consent. Personal autonomy.
\end{abstract}


Na assistência à saúde, o consentimento livre e esclarecido, também conhecido como "consentimento informado", não é ato isolado, mas processo constante de troca de informações entre médico e paciente, de modo a promover a participação ativa deste último em seu tratamento ${ }^{1,2}$. Compreende-se que toda decisão, para ser autônoma, precisa ser consciente, e portanto o ato de consentir só pode ser considerado válido se a equipe médica explicar de forma clara os benefícios e riscos de determinado procedimento ${ }^{3}$.

Em seu artigo 22, o Código de Ética Médica (CEM) ${ }^{4}$ obriga o profissional de saúde a obter o consentimento do paciente ou de familiar responsável após elucidá-lo acerca do procedimento a ser realizado, salvo em casos de risco iminente de morte. Seu artigo 34 o obriga ainda a informar o paciente acerca de seu diagnóstico, objetivos do tratamento, riscos e prognóstico, a não ser quando tal informação possa Ihe causar dano, situação em que a comunicação é direcionada ao representante legal. 0 paciente tem o direito de ser esclarecido sobre seu estado de saúde e tomar decisões livremente ${ }^{5}$.

No termo de consentimento livre e esclarecido (TCLE) devem constar todas as informações pertinentes ao caso clínico. $O$ documento visa assegurar a autonomia do paciente e comprovar que as informações foram transmitidas a ele. Moser ${ }^{6}$ destaca ainda que a tomada de decisão exige que o doente seja devidamente informado não só sobre seu diagnóstico, mas também sobre as alternativas terapêuticas. Na literatura podem ser encontrados dois enfoques sobre o TCLE: o da assistência à saúde (empregado neste estudo) e o das pesquisas envolvendo seres humanos.

$\mathrm{Na}$ assistência à saúde, o TCLE tem duas finalidades: jurídica, para eventual defesa do profissional, e ética, como processo contínuo de esclarecimento na relação entre médico e paciente, protegendo a autodeterminação deste último ${ }^{2}$. Em estudos com seres humanos, os princípios do consentimento, conforme definidos no item II.5 da Resolução 466/2012 do Conselho Nacional de Saúde $(\mathrm{CNS})^{7}$, são semeIhantes aos da assistência. Trata-se de anuência do participante da pesquisa e/ou de seu representante legal, livre de vícios (simulação, fraude ou erro), dependência, subordinação ou intimidação, após esclarecimento completo e pormenorizado sobre a natureza da pesquisa, seus objetivos, métodos, benefícios previstos, potenciais riscos e o incômodo que esta possa acarretar?

O TCLE utilizado na assistência deve ainda esclarecer sobre intervenções médicas, tratamentos e eventuais insucessos e riscos dos procedimentos - uma das principais dificuldades encontradas.
Profissionais da saúde muitas vezes têm dúvidas sobre quais informações transmitir ao paciente e como obter o consentimento informado ${ }^{8}$.

Levando em conta a relevância do TCLE para a relação médico-paciente, deve-se considerar a forma como o documento é redigido. Estudo com enfoque na pesquisa concluiu que no Brasil muitos indivíduos não conseguem ler e compreender totalmente o termo de consentimento, o que pode ser observado também na assistência à saúde ${ }^{9}$. Outra investigação apontou ainda a complexidade das informações, o uso de termos técnicos e a grande quantidade de páginas como fatores que prejudicam a compreensão do $\operatorname{TCLE}^{10}$.

Pesquisa com enfermeiros que trabalham em situação crítica apontou problemas éticos na transmissão de informações, ligados à tomada de decisões e à autodeterminação do paciente ${ }^{11}$. Sua autora chama atenção para a relevância do esclarecimento, já que as deliberações se baseiam na informação prestada. Outro estudo ressalta os problemas de comunicação entre equipe multiprofissional e paciente, especialmente envolvendo notícias difíceis, que, apesar de constantes na rotina de trabalho, geram desconforto em muitos médicos, que não se sentem preparados para revelá-las de modo adequado ${ }^{12}$.

Diante da importância do TCLE para profissionais e paciente, este estudo visa fomentar discussões em espaços de formação da comunidade hospitalar e acadêmica, no intuito de promover avanços e dar visibilidade ao significado desse documento. Para tanto, busca-se compreender como o termo de consentimento livre e esclarecido é percebido e utilizado na assistência à saúde.

\section{Método}

Trata-se de revisão de literatura cujo levantamento bibliográfico abrangeu o período de janeiro de 2013 a abril de 2018. Foram selecionados nas bases de dados Scientific Electronic Library Online, PubMed e Literatura Latino-Americana e do Caribe em Ciências da Saúde artigos que tinham como tema central o TCLE. Utilizaram-se os descritores "consentimento livre e esclarecido" e "consentimento informado".

A pesquisa resultou em 40 artigos, 11 publicados em 2013, 9 em 2014, 9 em 2015, 7 em 2016 e 4 em 2017. Foram desconsiderados os textos em que o TCLE, apesar de mencionado, não era o assunto principal. Para analisar os artigos selecionados, 
considerou-se o trabalho de autores que desenvolveram conceitos importantes para pensar a temática, ainda que em publicações anteriores a 2013.

\section{Referencial teórico}

\section{Princípios bioéticos e literatura}

No espaço hospitalar, os cuidados especializados para tratamento de condições crônicas ou agudas exigem a comunicação de notícias difíceis. Neste cenário, a bioética e a ética orientam os cuidados em direção ao respeito pela dignidade humana, com responsabilidade e prudência, garantindo os direitos do paciente.

Segundo Goldim ${ }^{13}$, a palavra "bioética" surge em 1927 em artigo publicado por Fritz Jahr, que a descreve como o reconhecimento de que se deve respeitar todo ser vivo como fim em si mesmo. Depois, contam Oliveira, Oliveira e Oliveira ${ }^{14}$, a palavra é usada por Potter nos anos 1970 para se referir a uma ciência multi e transdisciplinar que considera o ser humano como plenamente capaz de decidir sobre a melhor conduta para desenvolver seu projeto de vida.

O advento da bioética está ligado a conquistas de direitos humanos e à necessidade de controlar abusos e resolver conflitos morais decorrentes dos avanços científicos e tecnológicos ${ }^{15}$. A partir da reflexão sobre essas questões, documentos começaram a ser elaborados para guiar a conduta em pesquisas e procedimentos médicos.

O Código de Nüremberg ${ }^{16}$, divulgado em 1947, surge como resposta às experiências brutais realizadas com seres humanos na Segunda Guerra Mundial. O texto, primeiro a ponderar questões éticas para pesquisas científicas, afirma que o consentimento voluntário do indivíduo é essencial. Posteriormente, outros documentos foram elaborados, como a Declaração de Helsinki ${ }^{17}$. Com seguidas atualizações, essa é a declaração internacional mais importante no controle ético de pesquisas com seres humanos. As principais revistas científicas a utilizam como base para suas diretrizes editoriais ${ }^{15}$.

Atualmente quatro princípios regem a bioética: beneficência (o profissional deve agir pelo bem da vida e da saúde); não maleficência (não causar dano a outra pessoa); justiça (todo ser humano tem o direito de ser atendido na medida de suas necessidades); e autonomia (direito do paciente ou representante legal de tomar as próprias decisões quanto a procedimentos diagnósticos e terapêuticas) ${ }^{14}$.
No Brasil, um dos documentos que regem a ética em procedimentos médicos é o $\mathrm{CEM}^{4}$, que traz garantias tanto para a equipe de saúde quanto para o paciente, não mais admitindo decisões únicas e peremptórias por parte do profissional. Seguindo a manifestação de aceite consciente e bilateral, o esclarecimento do paciente e a documentação dão transparência à intervenção médica, registrando sua extensão e os possíveis insucessos do procedimento realizado ${ }^{14}$.

A Recomendação do Conselho Federal de Medicina (CFM) $1 / 2016^{1}$ valida e torna o TCLE fundamental para que o consentimento seja obtido sem vícios ou influências. A Recomendação ${ }^{1}$ ainda fornece orientações éticas complementares para situações de emergência, recusas, possibilidade de transtornos psicológicos causados pela informação, riscos à saúde pública e preexistência de transtornos mentais.

Outro documento importante é a Resolução CNS 466/2012 ${ }^{7}$, fundamentada no respeito à dignidade humana e na proteção de participantes de pesquisas, reconhecendo sua vulnerabilidade e assegurando que sua contribuição e permanência no estudo ocorram por manifestação livre e expressa. Todos esses documentos destacam o esclarecimento e o registro de procedimentos como meios para valorizar o princípio bioético da autonomia, essencial nas práticas de saúde.

\section{Autonomia}

Quando busca ajuda, o paciente encontra-se física e mentalmente fragilizado, tornando-se vulnerável, coagido a tomar decisões e a aceitar tratamentos que em outras circunstâncias talvez não escoIhesse ${ }^{18}$. Nesse sentido, o princípio da autonomia é tentativa de evitar que o cidadão seja submetido a atrocidades, violências e abusos em momento de fragilidade ${ }^{19}$. O indivíduo hospitalizado, ao se afastar de sua rede de convívio, que lhe dá confiança e segurança, torna-se ainda mais vulnerável. Os profissionais que lhe fornecem os cuidados necessários não conhecem sua história, suas expectativas, seus anseios e projetos de vida, o que compromete sua capacidade de decidir sobre questões relacionadas ao tratamento ${ }^{18,20}$.

Associa-se a vulnerabilidade à falta de autonomia do paciente durante a internação hospitalar, à própria doença, à falta de informações e de opções de terapêutica, além da ausência de controle sobre seu próprio corpo e mente ${ }^{20}$. Além disso, a possibilidade de ser considerado incapaz de tomar decisões e escolher tratamentos compatíveis com seus projetos 
de vida pode aumentar ainda mais sua fragilidade. Cada indivíduo sabe o que mais lhe atinge, tem noção de seus limites físicos e emocionais diante de procedimento médico e, por isso, cabe a ele decidir quais desconfortos são válidos em comparação com possíveis benefícios ${ }^{21}$. Assim, apesar da passividade, impotência e fragilidade experimentadas em internações e tratamentos, é direito do paciente escolher, aceitando ou recusando qualquer procedimento ${ }^{22}$.

O sujeito autônomo é aquele que pode decidir considerando seus princípios, valores, crenças e percepções, ponderando todos os fatores que interferem em sua capacidade de escolha ${ }^{23}$. Com informações precisas, o paciente tem poder para garantir o respeito à sua autonomia ${ }^{24}$. Por isso, desde o primeiro contato, é importante que a equipe médica transmita informações verdadeiras e completas, cumprindo o devido processo de consentimento livre e esclarecido ${ }^{25}$.

Estudo sobre conhecimento e voluntariedade para participar em pesquisas concluiu que entendimento inadequado ou desconhecimento de informações específicas contidas no TCLE prejudicam a autonomia do indivíduo ${ }^{26}$. Na assistência à saúde, a falta de esclarecimento prejudica a relação entre médico e paciente, já que a escolha livre e autônoma do enfermo depende das possibilidades que o profissional lhe apresenta. Se apenas uma possibilidade é assinalada, a decisão torna-se peremptória, pois a alternativa é tão somente a recusa do tratamento ${ }^{14}$.

Cabe observar, porém, que há exceções na prática clínica - por exemplo, quando o paciente não aceita a transfusão de sangue. Nesse caso, o indivíduo com possibilidade de cura, correndo risco de morte e sem alternativas terapêuticas não tem direito de decidir, pois o médico tem obrigação legal e ética de realizar o procedimento. O Conselho Regional de Medicina do Estado de São Paulo, na Consulta 35.605/2010, com parecer subscrito pelo conselheiro Caio Rosenthal, recomenda:

Pacientes adeptos da religião de testemunha de Jeová idosos, menores, com ou sem discernimento de expressar vontade, esgotadas as técnicas substitutivas de transfusão de sangue, não restando outra alternativa e ocorrendo risco de vida, o profissional médico que os assiste e a instituição hospitalar têm o dever legal e ético de realizar a transfusão independente da recusa dos pacientes ou dos responsáveis legais ${ }^{27}$.

Ou seja, a autonomia do paciente pode ser rejeitada quando há risco iminente de morte e chances de cura, caso em que seu consentimento não precisa ser obtido. Nessas situações, a desconsideração da vontade do paciente fica legitimada, pois seria até recriminada pelos profissionais da saúde e pela coletividade a conduta do médico que, diante da negativa do paciente, fique a seu lado no leito, em atitude solidária, aguardando o momento da morte. O médico não é um consolador e sim um profissional altamente treinado para administrar as condições de saúde do paciente e realizar procedimentos de intervenções rápidas e seguras. É, por assim dizer, o profissional da vida ${ }^{28}$.

Se o paciente não tiver condições de autogoverno e autodeterminação - como menores de idade ou alguém que se encontra em coma -, deverá ser legalmente representado por familiares ou terceiros legitimados ${ }^{14}$. Por questões éticas, ainda que nesses casos o pedido de consentimento seja feito a representantes legais, ninguém substitui a própria pessoa na decisão sobre qualquer conduta, ainda que a responsabilidade se estenda a todos os envolvidos, inclusive à sociedade e ao Estado ${ }^{29}$. Por isso, com maiores de idade, quando o paciente e seu representante manifestam decisões distintas, prevalece o direito do primeiro. Desse modo, a vontade do enfermo só será menor se esbarrar nos preceitos do CEM, se o próprio paciente autorizar o representante a decidir, ou se o profissional de saúde julgar que o doente não está em juízo perfeito para tomar decisões ${ }^{14}$.

No momento da internação e do tratamento, alguns indivíduos não têm condições cognitivas e físicas para consentir, o que se agrava ainda mais no caso de pacientes que experimentam dor e medo ${ }^{8}$. Este último influencia a tomada de decisão, limitando a autonomia e a voluntariedade, uma vez que o doente pode se sentir coagido pelo receio de ficar sem tratamento ${ }^{18}$. Ou seja, há perspectiva de coação na relação médico-paciente, principalmente entre usuários do Sistema Único de Saúde, que podem se sentir obrigados a aceitar uma terapêutica por medo de perder o acompanhamento caso discordem ${ }^{3}$.

A educação em saúde pode melhorar o processo de tomada de decisão na assistência, sendo muito importante em casos nos quais o profissional ou a instituição precisam dar ao paciente o máximo de informações sobre as perspectivas possíveis. Com conhecimento, o sujeito pode pensar, tomar decisões e assumir seu ponto de vista ${ }^{30}$. Essa educação deve priorizar o respeito aos direitos humanos e a construção de valores, funcionando como ação cultural para emancipar e empoderar os sujeitos ${ }^{20}$. 
Entendendo adequadamente as informações e o TCLE, o paciente pode manifestar sua voz, história e necessidades, transformando-se em sujeito de direitos ${ }^{31}$. Isso é importante porque, quando o termo de consentimento é mal compreendido, a voluntariedade do processo fica prejudicada ${ }^{32}$. Para exercer sua autonomia, o indivíduo deve receber informações de forma clara e precisa, com vocabulário simples e elucidação de possíveis dúvidas ${ }^{14}$.

\section{Termo de consentimento livre e esclarecido}

O consentimento informado é parte central da bioética e de seu rigor ao exigir respeito à liberdade, à autonomia e à autodeterminação do paciente ${ }^{33}$. Ele ganhou força ao garantir que, tendo o enfermo condições mínimas, ninguém pode decidir por ele e, caso não consiga, esse direito é passado a familiar ou representante legal, mas não aos médicos.

O TCLE engloba direitos de liberdade, privacidade e escolha individual ${ }^{5}$. Seu objetivo é promover a participação e a autorização esclarecida, ativa e autônoma do paciente ${ }^{34}$, fornecendo informações apropriadas, como benefícios, riscos, consequências e alternativas terapêuticas ${ }^{20}$. Como apontam Sousa, Araújo e Matos, o verdadeiro consentimento informado, em que há o envolvimento dos doentes e a partilha consciente de responsabilidade, é o único caminho para uma medicina de qualidade e para a defesa dos direitos dos doentes e dos profissionais de saúde ${ }^{35}$.

O processo de consentimento livre e esclarecido vai além do documento assinado pelo paciente. Ele deve garantir o exercício da autonomia pelo conhecimento de indicações e alternativas terapêuticas. Por trás da formalidade do TCLE deve haver respeito integral ao enfermo, permitindo que ele conheça totalmente seu estado de saúde e que suas decisões de tratamento sejam acatadas, ainda que divirjam da posição da equipe médica ${ }^{20}$.

Em estudos científicos, de acordo com o inciso XX do artigo 2o da Resolução CNS 510/2016, o processo de consentimento é pautado na construção de relação de confiança entre pesquisador e participante da pesquisa, em conformidade com sua cultura e continuamente aberto ao diálogo e ao questionamento, não sendo o registro de sua obtenção necessariamente escrito ${ }^{36}$. Rodrigues Filho, Prado e Prudente afirmam que o TCLE é um documento complexo, que se desdobra em vários elementos, transformando sua proposição em um processo de esclarecimento e respeito à dignidade da pessoa humana ${ }^{37}$. É fundamental certificar-se de que a informação foi compreendida ou se são necessárias informações adicionais ${ }^{33}$, pois a capacidade de consentir depende do entendimento do paciente ${ }^{20}$.

Estudo sobre o TCLE em pesquisas concluiu que nem todos os participantes que assinaram o documento realmente entenderam todas as informações, o que prejudica a decisão autônoma ${ }^{38}$. A assinatura por si só não garante que o consentimento foi livre, autônomo e voluntário, e que o paciente compreendeu todos os riscos e benefi$\operatorname{cios}^{39}$. Fatores como estresse, nível educacional, vulnerabilidade econômica e acesso a serviços de saúde interferem no processo.

O consentimento só tem efetividade se feito com liberdade, sem coações físicas, morais ou tempo limitado para reflexão, o que não significa que o médico não possa aconselhar o paciente para que este entenda melhor sua situação ${ }^{33}$. 0 consentimento também pode ser implícito ou explícito ${ }^{8}$. 0 primeiro pode ser dado por meio de linguagem não verbal, por exemplo, com gestos que manifestam movimento autônomo em direção aos procedimentos e ao tratamento. O segundo é dado verbalmente ou por escrito. Mesmo em atendimentos virtuais (telessaúde), já autorizados por alguns conselhos, o TCLE deve ser solicitado, de modo a manter os princípios éticos e legais na assistência à saúde ${ }^{40}$.

Como aponta Miziara, não há regras fixas para se obter o consentimento em todos os procedimentos médicos, e tampouco formulários próprios para todos eles, mas nos casos em que o risco existe $e$ não se tem um formulário adequado, o médico deve, como boa prática, anotar no prontuário do paciente que o "processo de consentimento" foi estabelecido $^{41}$. Ademais, o TCLE pode ser revisto, reajustado ou revogado a qualquer momento, se assim desejar o paciente. Caso o sujeito permaneça em silêncio, sem aprovar ou reprovar qualquer decisão, o julgamento em relação aos procedimentos deve ser transferido ao médico assistente ${ }^{14}$.

O erro mais comum no processo de consentimento é utilizar termos técnicos, inacessíveis ao paciente ou participante de pesquisa leigo ${ }^{42}$. Vários motivos podem impedir a compreensão adequada, como limitações intelectuais do paciente ou dificuldade do médico em explicar jargões da área da saúde. O medo também pode influenciar o processo, com mecanismos de defesa como negação, ilusões ou falsas crenças ${ }^{8}$.

Contextualizar as informações, ajustando-as à capacidade de entendimento do indivíduo, é o melhor método para obter o consentimento informado ${ }^{43}$. Nesse sentido, escrever o TCLE é tarefa 
desafiadora, visto que cada paciente tem suas particularidades. A redação exige conhecimento, sensibilidade e trabalho em equipe, para que o texto seja esclarecedor e cuidadoso com os seres humanos envolvidos ${ }^{42}$.

Para facilitar a compreensão do TCLE, pode-se acrescentar recursos audiovisuais, como vídeos educacionais que ajudem o paciente a entender o procedimento proposto ${ }^{44}$. A Resolução CNS 510/2016 prevê, em seu artigo 5으, a utilização de meios alternativos, permitindo que o consentimento seja realizado por meio de sua expressão oral, escrita, língua de sinais ou de outras formas que se mostrem adequadas, devendo ser consideradas as características individuais, sociais, econômicas e culturais da pessoa $^{36}$. Garantir ambiente acolhedor também é importante, uma vez que o empenho do médico em promover o debate com o paciente facilita o entendimento de pontos importantes ${ }^{3}$.

No Brasil, o TCLE é muitas vezes visto de forma distorcida, sendo suas informações consideradas como forma de prevenir ações judiciais em caso de maus resultados do procedimento ${ }^{2,8,32,45}$. Todavia, o documento não pode ser transformado em conjunto de termos técnicos para proteção do médico; ele deve ser claro e fomentar a solidariedade ao paciente em todas as fases do tratamento ${ }^{46}$. Forma adequada de evitar processos judiciais é desenvolver comunicação nítida com o paciente ${ }^{46}$.

Quando a relação se baseia na perspectiva de que o profissional é a autoridade e o paciente deve apenas obedecer, a cooperação entre as partes é afetada, tornando o tratamento algo imposto pela equipe médica ${ }^{18}$. Até pouco tempo, o médico era visto como provedor unilateral do bem-estar do paciente, mas na concepção atual este ultimo é coautor e divide responsabilidades nas escolhas ${ }^{15}$. $\mathrm{Na}$ adequada relação médico-paciente, as decisões são tomadas em conjunto ${ }^{46}$.

O consentimento é direito moral do paciente e obrigação para o profissional da saúde. Como afirma Clotet, sendo a interação entre médico e paciente um relacionamento contratual que implica direitos e deveres para ambas as partes, o médico não pode prescindir das decisões do paciente sempre que seu estado permitir expressá-las, devendo reconhecê-lo como um ser autônomo e livre ${ }^{47}$. Diante dessa autonomia do paciente, surgem questões burocráticas, e é nesse sentido que o TCLE pode ter intensa carga jurídica, resguardando pacientes e médicos.

Todavia, no hospital, afastado do convívio social e familiar, com limitações físicas e laborais, o sujeito experimenta medo e sensações de incapacidade ${ }^{20}$. Nesse contexto, a própria linguagem biomédica, impregnada de jargões específicos e terminologia científica, dificulta a apreensão completa dos aspectos relacionados ao seu estado de saúde ${ }^{48}$, muitas vezes desequilibrando a relação médico-paciente. $A$ falta de diálogo entre profissionais da saúde e pacientes demonstra que a comunicação é frequentemente menosprezada na relação de cuidado ${ }^{18}$.

Médico e paciente têm linguagens diferentes, e os modos de expressão do enfermo são muitas vezes desvalorizados em ambientes da saúde. No entanto, não se deve admitir que essa assimetria seja usada para negar a liberdade de decisão do indivíduo, desconsiderando seus projetos de vida e capacidade de agir ${ }^{20}$. Desse modo, a relação médico-paciente deve considerar os desejos do doente e dar segurança ao profissional, evitando confrontos e ações judiciais ${ }^{2}$, sendo o termo de consentimento parte desse processo ${ }^{45}$.

Apesar da exigência ética e jurídica, não é necessário nem aconselhável que o TCLE seja assinado para todos os procedimentos, já que, além de não haver garantias de que o documento escrito evitaria demandas judiciais, pode ainda distanciar o paciente e criar desconfiança. Se elaborado e atualizado de forma adequada, registrando as informações transmitidas e a participação do doente nas decisões terapêuticas, o prontuário pode servir como prova de que foi cumprido o dever de informar. Seu valor ético e legal é análogo ao do TCLE, que não consegue prever todas as possibilidades de intercorrências ou complicações do caso ${ }^{2}$. Por isso, como documento imprescindível na atividade médica, o prontuário deve conter todos os fatos, resultados de exames clínicos e complementares e hipóteses diagnósticas ${ }^{49}$.

Entende-se que o TCLE, ainda que muitas vezes usado com a finalidade de proteger juridicamente o médico, foi criado para preservar princípio fundamental da bioética: a autonomia. No entanto, a ideia de valorizar tal princípio não se restringe a esse documento, uma vez que a autonomia é o fundamento da relação médico-paciente e deve estar presente durante todo o tratamento.

\section{Considerações finais}

O $\mathrm{CEM}^{4}$ obriga o esclarecimento e consentimento do paciente, que deve ter autonomia sobre sua saúde. No entanto, uma vez que depende do dever dos profissionais de passar informações pertinentes de forma compreensível, essa autonomia 
pode ser limitada, prejudicando o poder de decisão do sujeito. Tal limitação não deveria ocorrer, visto que o mesmo CEM, em seu artigo 31, veda ao profissional de saúde desrespeitar o direito do paciente (...) de decidir livremente sobre a execução de práticas diagnósticas ou terapêuticas, salvo em caso de iminente risco de morte ${ }^{4}$, diante do qual a decisão é da equipe que o acompanha.

Há algumas dificuldades na utilização adequada do TCLE. Dentre elas está a fragilidade do vínculo entre paciente e profissional de saúde, principalmente no que se refere à comunicação, cuja deficiência prejudica o entendimento do doente sobre seu quadro clínico, diminuindo sua capacidade de opinar sobre o tratamento. Essa situação pode ser agravada pela carga emocional da internação, que amplia incertezas e temores e intensifica a vulnerabilidade, comprometendo a assistência.

A partir dos artigos analisados, percebeu-se ainda que o TCLE tem sido usado para proteger não só o paciente, mas também o profissional da assistência. Porém, ainda é escasso o conhecimento de médicos e enfermos sobre a real função do documento e as consequências éticas de seu uso no ambiente da saúde.

A autodeterminação ou autonomia só é exercida quando nenhum procedimento terapêutico é realizado sem consentimento verbal ou escrito do paciente ou representante legal. Para tanto, é necessário considerar as particularidades envolvidas e ter cuidado com a comunicação, que deve ser estabelecida com linguagem clara e compreensível, livre de termos técnicos, que permita ao doente apreender todos os aspectos importantes para a tomada de decisão. Por fim, ressalta-se a relevância de que tal temática seja mais discutida, na medida em que pacientes devem compreender seus direitos e médicos devem valorizar o processo de consentimento, sendo capacitados a utilizar adequadamente instrumentos como o TCLE.

\section{Referências}

1. Conselho Federal de Medicina. Recomendação CFM no 1/2016. Dispõe sobre o processo de obtenção de consentimento livre e esclarecido na assistência médica [Internet]. Brasília: CFM; 2015 [acesso 8 jun 2018]. Disponível: https://bit.ly/2P6niV7

2. Minossi JG, Silva AL. Medicina defensiva: uma prática necessária? Rev Col Bras Cir [Internet]. 2013 [acesso 9 jun 2018];40(6):494-501. DOI: 10.1590/S0100-69912013000600013

3. Ugarte ON, Acioly MA. O princípio da autonomia no Brasil: discutir é preciso. Rev Col Bras Cir [Internet]. 2014 [acesso 8 jun 2018];41(5):274-7. DOI: 10.1590/0100-69912014005013

4. Conselho Federal de Medicina. Código de Ética Médica: Resolução CFM no 1.931/09 [Internet] Brasília; CFM; 2010 [acesso 14 jun 2018]. Disponível: https://bit.ly/2WTi9E0

5. Paiva PA, Costa SM, Dias OV, Lopes VSVBV, Souto DGB, Silva DL. Experiência do comitê de ética em pesquisa de uma universidade pública de Minas Gerais, Brasil. Rev. bioét. (Impr.) [Internet]. 2015 [acesso 8 jun 2018];23(1):169-77. DOI: 10.1590/1983-80422015231057

6. Moser A. Biotecnologia e bioética: para onde vamos? 4a ed. Petrópolis: Vozes; 2004.

7. Conselho Nacional de Saúde. Resolução CNS no 466, de 12 de dezembro de 2012. Aprova diretrizes e normas regulamentadoras de pesquisas envolvendo seres humanos. Diário Oficial da União [Internet]. Brasília, no 12, p. 59, 13 jun 2013 [acesso 10 jun 2018]. Disponível: https://bit.ly/2FmqLgw

8. Miziara ID. Ética para clínicos e cirurgiões: consentimento. Rev Assoc Méd Bras [Internet]. 2013 [acesso 8 jun 2018];59(4):312-5. DOI: 10.1016/j.ramb.2013.06.007

9. Lobato L, Caçador BS, Gazzinelli MF. Legibilidade dos termos de consentimento livre e esclarecido em ensaios clínicos. Rev. bioét. (Impr.) [Internet]. 2013 [acesso 8 jun 2018];21(3):557-65 DOI: $10.1590 /$ S1983-80422013000300020

10. Meneguin S, Ayres JA. Percepção do termo de consentimento pelos participantes de ensaios clínicos. Invest Educ Enferm [Internet]. 2014 [acesso 9 jun 2018];32(1):97-102. Disponível: https://bit.ly/3fZ1Pcf

11. Nunes L. Problemas éticos identificados por enfermeiros na relação com usuários em situação crítica. Rev. bioét. (Impr.) [Internet]. 2015 [acesso 8 jun 2018];23(1):187-99. DOI: 10.1590/1983-80422015231059

12. Souza DB. Aspectos éticos e bioéticos na comunicação de notícias difíceis por médicos residentes da clínica cirúrgica em um hospital do sul do Brasil [dissertação] [Internet]. Santa Maria: Universidade Federal de Santa Maria; 2019 [acesso 12 abr 2020]. Disponível: https://bit.ly/30DYg4U

13. Goldim JR. Bioética: origens e complexidade. Rev HCPA [Internet]. 2006 [acesso 14 jun 2018];26(2):86-92. Disponível: https://bit.ly/3fYYhXA

14. Oliveira EQ Jr, Oliveira EQ, Oliveira PBQ. Autonomia da vontade do paciente $\times$ autonomia profissional do médico. Relampa [Internet]. 2013 [acesso 9 jun 2018];26(2):89-97. Disponível: https://bit.ly/32XPXDX

15. Garrafa V, Prado MM. Alterações na Declaração de Helsinque: a história continua. Rev. Bioética [Internet]. 2007 [acesso 10 jun 2018];15(1):11-25. Disponível: https://bit.ly/3fZv6n4 
16. Nüremberg Military Tribunals. Trials of war criminals before the Nüremberg Military Tribunals [Internet]. Nüremberg: Nüremberg Military Tribunals; 1949 [acesso 31 out 2019]. v. 2. Disponível: http://bit.ly/32crMgY

17. Associação Médica Mundial. Declaração de Helsinki [Internet]. Helsinki: AMM; 1964 [acesso 15 maio 2020]. Disponível: https://bit.ly/2F2rzHo

18. Bittencourt ALP, Quintana AM, Velho MTAC, Goldim JR, Wottrich LAF, Cherer EQ. A voz do paciente: por que ele se sente coagido? Psicol Estud [Internet]. 2013 [acesso 9 jun 2018];18(1):93-101. DOI: $10.1590 / S 1413-73722013000100010$

19. Borges LO, Barros SC, Leite CPRLA. Ética na pesquisa em psicologia: princípios, aplicações e contradições normativas. Psicol Ciênc Prof [Internet]. 2013 [acesso 11 jun 2018];33(1):146-61. DOI: 10.1590/S1414-98932013000100012

20. Silva MF. Consentimento informado: estratégia para mitigar a vulnerabilidade na assistência hospitalar. Rev. bioét. (Impr.) [Internet]. 2017 [acesso 11 jun 2018];25(1):30-8. DOI: $10.1590 / 1983-80422017251163$

21. Fernandes CF, Pithan LH. O consentimento informado na assistência médica e o contrato de adesão: uma perspectiva jurídica e bioética. Rev HCPA [Internet]. 2007 [acesso 8 jun 2018];27(2):78-82. Disponível: https://bit.ly/39sefao

22. Clotet J. O respeito à autonomia e aos direitos dos pacientes. Rev Assoc Méd Rio Gd Sul [Internet]. 2009 [acesso 13 ago 2020];53(4):432-5. Disponível: https://bit.ly/3g607oT

23. Cosac DCS. Autonomia, consentimento e vulnerabilidade do participante de pesquisa clínica. Rev. bioét. (Impr.) [Internet]. 2017 [acesso 8 jun 2018];25(1):19-29. DOI: 10.1590/1983-80422017251162

24. Leite RAF. Direito à informação em saúde: análise do conhecimento do paciente acerca de seus direitos [dissertação] [Internet]. Ribeirão Preto: Universidade de São Paulo; 2010 [acesso 12 jun 2018]. DOI: 10.11606/D.22.2010.tde-16112010-110825

25. Clotet J. Por que bioética? Bioética [Internet]. 1993 [acesso 8 jun 2018];1(1):14-9. Disponível: https://bit.ly/2ZX7aLL

26. Lobato L, Gazzinelli MF, Gazzinelli A, Soares AN. Conhecimento e voluntariedade para participação em pesquisas: um estudo descritivo com participantes de um ensaio clínico. Cad Saúde Pública [Internet]. 2014 [acesso 8 jun 2018];30(6):1305-14. DOI: 10.1590/0102-311X00127813

27. Conselho Regional de Medicina do Estado de São Paulo. Consulta no 35.605/10. Garantia constitucional e ética. Liberdade de consciência e crença e autonomia profissional. Não incidência em infração ética [Internet]. São Paulo: Cremesp; 22 nov 2011 [acesso 10 jun 2018]. Disponível: https://bit.ly/3fZeZ99

28. Oliveira EQ Jr, Oliveira EQ, Oliveira PBQ. Op. cit. p. 95.

29. Kipper DJ. Ética em pesquisa com crianças e adolescentes: à procura de normas e diretrizes virtuosas. Rev. bioét. (Impr.) [Internet]. 2016 [acesso 8 jun 2018];24(1):37-48. DOI: 10.1590/1983-80422016241104

30. Lefevre F, Lefevre AMC, Cavalcanti CCTJ. A educação democrática e sua aplicação ao campo da saúde. Saúde Soc [Internet]. 2015 [acesso 14 jun 2018];24(supl 1):176-83. DOI: 10.1590/ S0104-12902015S01015

31. Freitas MAS. Bioética e direito no sistema de saúde brasileiro: a prática do consentimento informado nos cenários da oncologia de um hospital do SUS e um particular [tese] [Internet]. São Paulo: Universidade de São Paulo; 2017 [acesso 9 jun 2018]. DOI: 10.11606/T.6.2017.tde-14072017-111926

32. Melendo MP, Viegas K, Souza EN, Caregnato RCA. Termo de consentimento informado: entendimento do paciente cirúrgico. Acta Paul Enferm [Internet]. 2016 [acesso 9 jun 2018];29(3):291-7. DOI: 10.1590/1982-0194201600041

33. Sousa J, Araújo M, Matos J. Consentimento informado: panorama atual em Portugal. Rev Port Ortop Traum [Internet]. 2015 [acesso 8 jun 2018];23(1):6-17. Disponível: https://bit.ly/2CBmRQ0

34. Dias MP, Shinn C, Amaral L, Araújo MJ, Pinto A, Gonzalez P, Pinto D. Ciclo de melhoria de qualidade para aumentar a obtenção de consentimento informado em procedimentos de planeamento familiar. Rev Port Med Geral Fam [Internet]. 2014 [acesso 8 jun 2018];30(3):168-72. Disponível: https://bit.ly/32SIBBi

35. Sousa J, Araújo M, Matos J. Op. cit. p. 12.

36. Conselho Nacional de Saúde. Resolução CNS no 510, de 7 de abril de 2016. Dispõe sobre as normas aplicáveis a pesquisas em ciências humanas e sociais cujos procedimentos metodológicos envolvam a utilização de dados diretamente obtidos com os participantes ou de informações identificáveis ou que possam acarretar riscos maiores do que os existentes na vida cotidiana. Diário Oficial da União [Internet]. Brasília, 24 maio 2016 [acesso 10 jun 2018]. Disponível: https://bit.ly/39p1FIR

37. Rodrigues Filho E, Prado MM, Prudente COM. Compreensão e legibilidade do termo de consentimento livre e esclarecido em pesquisas clínicas. Rev. bioét. (Impr.) [Internet]. 2014 [acesso 8 jun 2018];22(2):325-36. p. 327. DOI: 10.1590/1983-80422014222014

38. Lobato L, Gazzinelli MF. O consentimento informado nos países em desenvolvimento é realmente autônomo? Um estudo descritivo com participantes de um ensaio clínico sobre helmintoses. Acta Bioeth [Internet]. 2015 [acesso 8 jun 2018];21(1):127-36. Disponível: https://bit.ly/2ZVeOWY

39. Assumpção C, Pinto NS, Velarde LGC, Nascimento OJM, Olej B. Compreensão do termo de consentimento em pesquisa clínica. Rev. bioét. (Impr.) [Internet]. 2016 [acesso 8 jun 2018];24(1):184-94. DOI: 10.1590/1983-80422016241120 
40. Rezende EJC, Tavares EC, Souza C, Melo MCB. Telessaúde: confidencialidade e consentimento informado. Rev Méd Minas Gerais [Internet]. 2013 [acesso 8 jun 2018];23(3):367-73. DOI: $10.5935 / 2238-3182.20130058$

41. Miziara ID. Op. cit. p. 313.

42. Romualdo VA, Bosque RM, Bettcher L, Viana FJM. O termo de consentimento e as pendências identificadas na apreciação ética pelo CEP-FHEMIG. Rev Méd Minas Gerais [Internet]. 2014 [acesso 8 jun 2018];24(supl 5):S71-5. DOI: 10.5935/2238-3182.20140076

43. Almeida LD. Efeito nocebo e consentimento informado contextualizado: reflexões sobre aplicação em oftalmologia. Rev. bioét. (Impr.) [Internet]. 2014 [acesso 8 jun 2018];22(3):427-33. DOI: 10.1590/1983-80422014223024

44. Souza MK, Jacob CE, Gama-Rodrigues J, Zilberstein B, Cecconello I, Habr-Gama A. Termo de consentimento livre e esclarecido (TCLE): fatores que interferem na adesão. ABCD Arq Bras Cir Dig [Internet]. 2013 [acesso 8 jun 2018];26(3):200-5. DOI: 10.1590/S0102-67202013000300009

45. Albuquerque R, Garrafa V. Autonomia e indivíduos sem a capacidade para consentir: o caso dos menores de idade. Rev. bioét. (Impr.) [Internet]. 2016 [acesso 8 jun 2018];42(3):452-8. DOI: 10.1590/1983-80422016243144

46. Santos OM. Termo de consentimento versus relação médico-paciente. Braz J Otorhinolaryngol [Internet]. 2014 [acesso 9 jun 2018];80(3):189-90. DOI: 10.1016/j.bjorl.2014.05.007

47. Clotet J. Op. cit. 2009. p. 433.

48. Silva MF. Op. cit. p. 35.

49. Cordeiro F. Quais os cuidados antes da operação? Termo de consentimento sempre? Rev Col Bras Cir [Internet]. 2013 [acesso 8 jun 2018];40(5):354-6. DOI: 10.1590/S0100-69912013000500001

\section{Participação dos autores}

Carolina Fernandes de Castro redigiu o manuscrito. Alberto Manuel Quintana orientou e, com Luísa da Rosa Olesiak e Mikaela Aline Bade München, colaborou na redação final do artigo.

\section{Correspondência}

Carolina Fernandes de Castro - Rua General Neto, 504, apt. 1.311 CEP 97050-240. Santa Maria/RS, Brasil.

\section{Carolina Fernandes de Castro - Mestranda - krol.castro@gmail.com} (iD) 0000-0002-7126-4527

Alberto Manuel Quintana - PhD - albertom.quintana@gmail.com (i) 0000-0001-7356-6142

Luísa da Rosa Olesiak - Doutoranda - luisa_drolesiak@hotmail.com (iD) 0000-0002-2635-2675

Mikaela Aline Bade München - Graduanda - mikaelaaline@hotmail.com (iD) 0000-0001-7610-0030 